\title{
DO CAMINHO DAS PEDRAS À BUSCA DE UM TRABALHO COLETIVO: FORMAÇÃO DE EDUCADORES AMBIENTAIS NA EDUCAÇÃO BÁSICA
}

\author{
Henrique Manoel Ramos Alberto ${ }^{1}$ \\ Icléia Albuquerque de Vargas²
}

\begin{abstract}
Resumo: O artigo apresenta uma pesquisa desenvolvida junto ao Programa de Pósgraduação em Ensino de Ciências (UFMS), com foco na formação continuada para educadores ambientais de uma escola da rede pública estadual de Mato Grosso do Sul. O objetivo foi proporcionar aos professores condições para melhor compreensão da Educação Ambiental como instrumento de transformação socioambiental por meio do desenvolvimento de atitudes conscientes diante das realidades locais. Dentro da modalidade qualitativa, optamos pela pesquisa colaborativa. Os resultados foram constatados por meio do envolvimento da comunidade escolar, bem como pela revisão de atitudes que enriqueceram a prática pedagógica.
\end{abstract}

Palavras-chave: Educação Ambiental; Formação de Professores; Trabalho Coletivo.

Abstract: The article presents the research developed with a post-graduation program in Science Education (UFMS), focusing on continual training of environmental educators at a public school in Mato Grosso do Sul. The objective was to provide teachers conditions for a better understanding of environmental education as an instrument of socio-environmental transformation through the development of conscious attitudes towards local realities. Under the qualitative modality, we chose collaborative research. The results were verified through the engagement of the school community, as well as the review of attitudes that enriched the pedagogical practice.

Keywords: Environmental Education; Teacher Training; Collective Work.

\footnotetext{
1 Universidade Federal de Mato Grosso do Sul/Secretaria de Estado de Educação de Mato Grosso do Sul. E-mail: hmralberto@gmail.com. Link para o Lattes: http://lattes.cnpq.br/8015287839385265

2 Universidade Federal de Mato Grosso do Sul. E-mail: icleiavargas12@gmail.com. Link para o Lattes: http://lattes.cnpq.br/8545121561786241
}

revista brasileira educação ambiental 


\section{Introdução}

A realidade dos docentes da escola pública brasileira contemporânea esbarra em várias questões que avançam para além da precariedade salarial. A infraestrutura da maioria das unidades escolares pode ser colocada como um dos grandes entraves para o desenvolvimento de educação de qualidade. A carência ou inexistência de recursos didático-pedagógicos também desponta como fator relevante que emperra o bom desenvolvimento das atividades docentes. Completa-se esse rol de obstáculos ao bom fluir da educação brasileira com a problemática da formação, inicial e continuada, de professores. Consideramos esta última questão como primordial e a mais complexa, pois envolve fatores de ordem social, cultural, histórica, além dos interesses do próprio profissional.

Para o caso específico da formação continuada sobre meio ambiente e Educação Ambiental, o que se vê na prática das escolas de educação básica, é que se trata de um assunto muitas vezes discutido apenas nos componentes curriculares de Geografia e Ciências. Questionamos, então, por que não aperfeiçoar o saber sobre o meio ambiente dos professores dessas áreas para atuarem como agentes multiplicadores e motivadores dentro das escolas? Isso valeria tanto para os colegas docentes quanto para os alunos, além de evidenciar que todos podem fazer a Educação Ambiental, construindo novas práticas nas instituições de ensino.

A formação de professores e a Educação Ambiental são assuntos muito discutidos nas escolas, mas ainda longe de alcançarem respostas. Questões que envolvem o meio ambiente e a educação apresentam mudanças lentas, talvez em função de interesses que abarcam o sistema produtivo vigente (GUIMARÃES,2012). Há muitas hipóteses, ainda passíveis de estudos, buscando alternativas para implantar na prática o que vem sendo discutido há anos.

Destacando a importância da formação continuada do professor, inclusive na própria instituição em que trabalha, neste artigo iremos expor alguns resultados levantados após a pesquisa realizada junto ao Programa de Pós-graduação em Ensino de Ciências da Universidade Federal de Mato Grosso do Sul, com área de concentração em Educação Ambiental, durante os anos letivos de 2016 e 2017. O objetivo geral da pesquisa foi proporcionar aos professores condições para melhor compreensão da Educação Ambiental como instrumento de transformação socioambiental para o desenvolvimento de atitudes conscientes diante das realidades locais, tendo como embasamento uma abordagem freireana (SAITO; FIGUEIREDO; VARGAS, 2014).

Ressaltamos que os dados e as práticas desenvolvidas com a pesquisa se constituíram em boas experiências que refletem resultados até a atualidade. O espaço investigado foi a Escola Estadual Amando de Oliveira que oferece ensino fundamental e médio, em Campo Grande, Mato Grosso do Sul.

O Projeto Político Pedagógico (PPP) da Escola indica que a comunidade escolar é bastante diversificada, caracterizada por uma população de 
trabalhadores do comércio, indústria e pequenos comerciantes. Os alunos são constituídos por crianças, adolescentes, jovens e adultos que somavam, em 2017, aproximadamente, 1100 estudantes, divididos em 30 turmas da Educação Básica. Atualmente o corpo docente é composto por 76 profissionais de diversas áreas do conhecimento (distribuídos entre coordenadores, professores regentes, professores de apoio, e readaptados ${ }^{3}$ ).

Pode-se destacar o nível de criticidade da equipe, sempre debatendo e questionando as decisões do grupo e aquelas oriundas do órgão central. Além disso, ressalta-se a participação maciça nos movimentos em busca por melhoria da educação e demais atividades proporcionadas pelo sindicato que representa a categoria.

Diante de uma proposta de pesquisa colaborativa, construímos quatro encontros destinados à formação continuada de professores. Ao grupo foi esclarecido o projeto de investigação, instigando os participantes à construção de ações a serem trabalhadas durante o percurso do período estudado.

Este artigo encontra-se assim organizado: inicialmente um rápido debate sobre a Educação Ambiental e as contribuições de Paulo Freire, seguido pelo relato dos encontros destinados à formação continuada de professores e, posteriormente, a discussão sobre os resultados.

\section{Educação Ambiental e problematização}

Acreditamos que a Educação Ambiental pode ser um caminho para o exercício do trabalho coletivo e a produção de conhecimentos nas instituições de educação básica, configurando-se como uma forma de esclarecimentos e melhor compreensão dos atuais problemas relacionados às questões socioambientais, promovendo a reflexão sobre suas possíveis causas e enveredando para o levantamento de proposições de soluções. Ela pode ser uma resposta à demanda gerada pela crise ambiental, atualmente reconhecida pela grande maioria das pessoas "mundo afora" (GUIMARÃES, 2012). Esta crise é abordada na obra de Leff (2012) e reafirmada por Guimarães (2012):

Parece-me ser a crise ambiental já um consenso mundial, tanto que é uma das principais pautas nas negociações internacionais. Hoje, a divergência é quanto à intensidade e à gravidade dessa crise e, principalmente, quanto às medidas corretivas a serem tomadas. Para uns, a crise será superada por pequenos acertos a serem realizados sobre o atual modo de produção, e esses acertos poderão ser viabilizados pela própria lógica de mercado. Para muitos outros, entre os quais me enquadro, trata-se de uma crise civilizatória de um modelo de sociedade e seu modo de produção (GUIMARÃES, 2012, p. 22).

\footnotetext{
${ }^{3}$ Professores readaptados são aqueles que, por motivo de saúde, exercem outra função em uma escola, como, por exemplo, de auxiliar de coordenação ou na biblioteca.
} 
Entretanto, avalia-se como salutar não atribuir à Educação Ambiental a prerrogativa de solucionar todos os problemas ambientais do mundo. Seria um pensamento ingênuo não considerar a necessidade de um empenho maciço para se transformar as realidades vividas, os pontos de vista e a ética que predominam nas relações entre sociedade e natureza.

A Educação Ambiental tem a responsabilidade sim de construir uma nova ética que possa ser entendida como ecológica, desde que esta se defina no embate democrático entre ideias e projetos que buscam a hegemonia na sociedade e no modo como esta produz e se reproduz, problematizando valores vistos como absolutos e universais. O que é bom, justo, certo e solidário para uma determinada comunidade e sua moral, pode não ser para outra que esteja em uma situação objetiva diversa. Agindo assim, a Educação Ambiental atua como base no princípio da responsabilidade com o outro, do escrúpulo, do bom senso e não no plano da imposição, da normatização e da culpabilização individual, objetivando a coerência de valores e condutas nas ações que realizamos ao procurarmos viver dignamente e resolvermos os problemas existenciais que nos colocamos (LOUREIRO, 2012, p. 59).

A citação acima vai exatamente ao encontro do proposto no referente trabalho, no qual as especificidades e adversidades de cada localidade devem ser levadas em consideração nos estudos envolvendo a Educação Ambiental, tendo o bom senso e a responsabilidade com o outro como prioridades na busca da mudança de valores. Ressaltando que não há um modelo prévio a ser seguido, e sim propostas e experiências que podem ser adaptadas ou utilizadas como inspiração a novas ideias.

Há de se ressaltar a importância do ambiente escolar para a Educação Ambiental. Porém, na prática ainda encontramos metodologias tradicionais, fragmentadas ou até mesmo que defendem a criação de uma disciplina específica para abordar a questão (GUIMARÃES, 2013).

A maior parte dos professores está sensibilizada contra a degradação da natureza, e se mobiliza, com empenho sincero, para enfrentar essa questão, mas as práticas resultantes geralmente são pouco eficazes para mudar, de forma significativa, a realidade mais imediata com a qual estão lidando e, reciprocamente, com uma realidade mais ampla. O melhor resultado, que não deixa de ser importante, mas que se revela insuficiente para o enfrentamento da crise ambiental, é a difusão de informações sobre a importância da preservação da natureza (GUIMARÃES, 2013, p. 40). 
Muitas vezes as práticas de Educação Ambiental escolar se revelam ineficazes. Acredita-se que isso pode estar relacionado, dentre outras causas, às ações individuais das disciplinas escolares, ou seja, à escassa interação entre os docentes das diversas áreas do conhecimento. Assim, para se trabalhar com as questões ambientais, tem-se o desafio da superação da fragmentação do conhecimento e a consequente busca pelo entendimento de maneira ampla. É necessário se pensar a Educação Ambiental como se fosse um guarda-chuva, que envolve todas as áreas, cada uma contribuindo a partir de sua especialidade para a construção de uma visão mais vasta sobre meio ambiente e como os problemas podem ser superados.

A instituição investigada reúne um grande grupo, incluindo professores dos anos iniciais do Ensino Fundamental ao Ensino Médio, bem como os servidores do corpo administrativo. Os próprios docentes, todos licenciados em suas áreas específicas, podem contribuir para a formação do coletivo.

Os procedimentos teórico-metodológicos propostos por Freire para instrumentalizar os professores na implementação de práticas docentes com a finalidade de promover a perspectiva crítico-transformadora são operacionalizados pela investigação temática e redução temática e necessitam de um coletivo de especialistas, tal qual podemos considerar os docentes das várias áreas do conhecimento que parametrizam disciplinas escolares, para serem consistentemente concretizados. $O$ desafio do trabalho de uma equipe, pelo menos multidisciplinar, é um imperativo para a ocorrência tanto da investigação como da redução temáticas, dado o caráter complexo, multifacetado, dos problemas envolvidos nas contradições sociais, de onde emergem temas geradores (DELIZOIKOV; DELIZOIKOV, 2014, p. 92).

$\mathrm{Na}$ Educação Ambiental encontramos diversos trabalhos embasados nas ideias e ideais de Paulo Freire, pautados em temas gerados com 0 propósito de um trabalho coletivo resultando em práticas conscientes.

Em um contexto de EA escolar o desenvolvimento do trabalho educativo pautado em temas geradores, representativos das relações entre sociedade, cultura e natureza, pode permitir a práxis pedagógica que é a reflexão e ação dos educandos e educadores sobre a realidade sócio-histórico-cultural vivida e a ser transformada - o que pode se dar por meio de processos formativos e práticas curriculares e didático pedagógicas freireanas (TORRES, FERRARI; MAESTRELLI, 2014, p. 16).

Ler obras de Paulo Freire é um exercício constante de revisão da prática docente, proporciona uma análise e revisão de postura, acertos e erros em nossas ações enquanto professores. Isso porque fazemos parte de uma geração que foi educada de "forma bancária" (FREIRE, 2015) e trazemos isso 
conosco. O ideal seria estarmos sempre com mentes abertas à aprendizagem, compreendendo até que ponto reproduzimos esse vício ao qual fomos expostos.

O educador problematizador tem a consciência de fazer parte de um contexto e estar em constante aprendizado, "a educação problematizadora se faz, assim, um esforço permanente através do qual os homens vão percebendo, criticamente, como estão sendo no mundo com que e em que se acham" (FREIRE, 2015, p. 100). Sendo assim, o educador-aprendiz é livre para rever constantemente suas atitudes e pensar e agir no coletivo.

No desenvolvimento da pesquisa, no que diz respeito à problematização, a primeira etapa realizada com o grupo na qual as pretensões do coletivo foram manifestadas, foi expressa pela "Oficina de Futuro", atividade proposta inicialmente pela ONG Instituto Ecoar (BRASIL, 2012), da qual constam as dinâmicas denominadas "Árvore dos Sonhos" e "Pedras no Caminho", utilizadas neste trabalho para identificar os "sonhos" presentes na escola, bem como as principais dificuldades para se atingir esses sonhos. A partir daí foi possível levantar os temas geradores que emergiram e que poderiam ser relacionados à Educação Ambiental, pois não se problematiza a realidade apenas para conhecê-la, problematiza-se para modificá-la (SAITO; FIGUEIREDO; VARGAS, 2014).

Ressalta-se que essa atividade foi feita com todos os professores da Escola Estadual Amando de Oliveira no início do ano letivo de 2016, em um dos dias da semana destinado à Jornada Pedagógica, conforme calendário das escolas da Secretaria de Estado de Educação de Mato Grosso do Sul (SEDMS).

Serão detalhados a seguir os encontros inclusos na formação de professores da Escola estudada.

\section{Encontros para formação de professores}

Durante o ano letivo de 2016 foram realizados quatro encontros para a construção da proposta apresentada. Tendo em mente o que foi colocado nas entrevistas, concorda-se que:

A questão da "formação de professores" poderá ser abordada pela perspectiva das finalidades da educação. A questão das finalidades inscreve-se no âmbito do discurso teleológico, isto é, aquele que responde ao "por quê". Ao adotarmos esse discurso denominado teleológico, entramos no domínio de sentido da ação como "autorização" de um sujeito concreto, isto é, o processo de construção de autoria de suas relações com a realidade, com o mundo e com outros sujeitos (ZUBEN, 2003, p. 62). 
Assim, há necessidade de se diagnosticar qual realidade estamos investigando, correspondendo aos anseios dos envolvidos e buscando atender às demandas do ambiente escolar, pois o comportamento humano é orientado para determinados fim, o que lhe confere "sentido" (ZUBEN, 2003).

Apesar de constatar a necessidade de se proporcionar maior número de encontros desse tipo, visando à construção coletiva, é importante destacar que a Secretaria de Educação (SED-MS) disponibiliza durante o ano letivo, apenas quatro oportunidades para formação de professores e, mediante a autorização da Direção escolar, pode-se aproveitar uma parte de cada um desses momentos para a realização dessa etapa da pesquisa, configurando os seguintes encontros:

- 1ํ Encontro (fevereiro de 2016) - Oficina de Futuro (Árvore dos Sonhos e Pedras no Caminho);

- 2ํㅡㄹ Encontro (abril de 2016) - Elaboração de ações;

- 3 o Encontro (agosto de 2016) - Preparo para a Feira Científica;

- $4^{\circ}$ Encontro (outubro de 2016) - Discussões sobre o PPP.

O primeiro encontro foi realizado durante uma Jornada Pedagógica da Rede Estadual de Ensino de Mato Grosso do Sul. Esse momento aconteceu em fevereiro de 2016, primeira semana do ano letivo, após o retorno dos professores das férias escolares. Foi muito oportuno para as discussões da rotina escolar, o estabelecimento de combinados e sugestões e definições de eventos e respectivas datas para o decorrer do ano letivo. Configurou-se como um relevante momento, pois a empolgação do início das atividades foi transformada em importantes contribuições, ocorrendo a apresentação de propostas para a realização de eventos, a exemplo da Feira Científica e Cultural, assim como a definição de avaliações diversas, dentre outras sugestões.

Em um dos dias da Jornada Pedagógica foi possível realizar as atividades da Oficina de Futuro, como explicado no tópico anterior. A metodologia desta atividade recomenda iniciá-la por meio de uma pergunta geradora. Para tanto, na ocasião foi proposta a seguinte questão: "Que escola nós queremos?"

A Oficina de Futuro foi realizada em dois momentos, ambos durante a primeira reunião da Jornada Pedagógica, sendo um momento no período matutino e outro no período vespertino na mesma data. Os professores do período noturno participaram em um desses turnos. Ao término da Oficina de Futuro do período matutino, houve o cuidado de se retirar os vestígios das contribuições dos docentes do turno, como o intuito de não influenciar o grupo do turno seguinte. Posteriormente, todas as contribuições foram reunidas para que a Árvore dos Sonhos fosse montada por completo, com o pronunciamento de todos os professores. Essa Árvore foi mantida exposta durante todo o ano letivo na Sala de Tecnologias Educacionais (STE), local frequentado por todos, 
onde haveria a possibilidade de se relembrar os relatos obtidos no momento de sua construção.

Antes de iniciar a Oficina de Futuro, uma professora readaptada que estava na função de apoio pedagógico sugeriu que fosse realizada uma reflexão com o grupo de professores, sobre os sonhos de cada um, e como eles poderiam se tornar metas. Em sua argumentação, essa professora questionou o fato de como iríamos discutir os sonhos da escola, para transformá-los em metas, se algumas pessoas nem haviam estabelecido as metas individuais em suas vidas. Sendo assim, foi feito um momento introdutório, priorizando a reflexão sobre os sonhos particulares e como transformá-los em metas. A professora de apoio conduziu essa discussão. Em um primeiro momento entregou uma folha de papel em branco para cada professor participante e solicitou que escrevessem três características pessoais que eles não suportavam mais em suas vidas e três qualidades próprias das quais se orgulhavam. Em um segundo momento, solicitou que dividissem o verso da folha em quatro partes, simbolizando o espiritual, o intelectual, o físico e o emocional/relacionamentos.

Os professores não precisavam socializar suas respostas, por se tratar de reflexões individuais. Mas, mesmo assim, alguns comentaram sobre o momento em si, sem entrar em particularidades. Uma professora, inclusive, sugeriu que, a partir das discussões, o que poderia ser melhorado dentro da escola seria o trabalho em grupo.

Após este primeiro momento, percebemos que os professores estavam mais compenetrados e aquela barreira inicial, manifestada durante a reunião pedagógica, aos poucos estava sendo rompida e todos se sentiam mais à vontade.

Combinamos que nesse momento seriam implementadas as duas primeiras etapas da Oficina do Futuro, ou sejam, a Árvore dos Sonhos e as Pedras no Caminho, para que pudéssemos realizar a dinâmica com todos os professores dos três períodos de funcionamento da escola ${ }^{4}$. Sendo que a terceira etapa, ou seja, o Plano de Ação ficaria para o segundo encontro de formação de professores.

Nos dois períodos na qual a dinâmica foi realizada os professores ficaram apreensivos no início, porém, assim que as primeiras contribuições foram surgindo, como se fosse algo automático, as expressões verbais foram fluindo e todos participaram elencando a escola que gostariam de ter. Surgiram as palavras e expressões a seguir para as duas Árvores dos Sonhos:

${ }^{4}$ Como não foi realizado um encontro específico no período noturno, os professores deste turno se distribuíram, podendo optar em participar no período matutino ou vespertino. 
Período Matutino: Produção; escola democrática e humana; alunos dedicados; aluno feliz; coletividade; participativa; mais internet; mais rendimento na aprendizagem; mais alunos motivados; seja necessária; família na escola; meio ambiente; escola exemplo; alunos bem-sucedidos; igualitária; inclusiva com as tecnologias; trabalho coletivo; escola com alunos motivados; melhorar os índices das avaliações externas; comprometimento; bons relacionamentos; planejamento.

Período vespertino: ambiente saudável; acolhedora; bem-conceituada; sala de vídeo; alunos mais conscientes da importância e valor da escola; alunos compromissados; alunos pensantes; respeito e valorização profissional em todos os sentidos; quadra coberta; laboratório de artes ou multidisciplinar; se colocar no lugar do outro; atividades práticas; estruturada; IDEB 7,0; inovadora; humanizadora; compromisso; educar com amor; amizades; ornamentada com plantas; amorosa; cidadã; comunitária; cooperação; professores motivados; ensino de excelência; mais alunos motivados; comprometimento; respeito.

Analisando as palavras e expressões mencionadas, percebe-se ser possível tecer algumas reflexões. Existem sonhos aparentemente simples mas existem empecilhos relacionados à burocracia, questões políticas e recursos financeiros para que possam ser concretizados - como, por exemplo, a existência de uma quadra coberta para a instituição, ou até mesmo uma rede de internet que funcione sem interrupções, revelando algumas necessidades relacionadas ao ambiente de trabalho e uma intenção de se conquistar condições básicas para exercer atividades comuns da escola com melhor qualidade.

Vários termos lembrados se relacionam à temática meio ambiente, ou seja, desde a necessidade de a escola disponibilizar ambientes mais adequados aos estudos, com conforto, bem como a melhoria das relações interpessoais, esta sinalizada pela palavra "respeito".

Havia a necessidade de um trabalho coletivo, visando à melhoria do ambiente escolar e à prática pedagógica, assunto também levantado durante a reunião. Na ocasião, como ainda não havia um conhecimento mais aprofundado do grupo e pelo grupo, não foi possível compreender tudo o que estava contido nas entrelinhas, mostrando que realmente havia embutido no discurso certo anseio sobre as questões apontadas. Apesar de muitos professores atuarem há tempos na escola, poucos se conhecem em profundidade e também poucos conhecem o ambiente de trabalho, a Escola. Agora existe maior possibilidade de se refletir o porquê deste anseio, após sua exposição, pois, por meio de observação, foi possível constatar um grupo de professores que, além da fragmentação do próprio currículo, estava trabalhando de maneira isolada.

Em relação às "Pedras no Caminho", emergiram as expressões expostas a seguir: 
Período Matutino: burocracia; fragmentação; famílias desestruturadas; comunicação/diálogo; falta de empatia; desistência; falta de incentivo da família; desmotivação; apatia do aluno; falta da família na escola; escola segmentada (ilhas); conhecimento prévio; hipocrisia política; entender a troca de conhecimento; autonomia da escola.

Período Vespertino: falta de recursos; ideologias opostas; trazer a família; acreditar no potencial de crescimento das pessoas; divergências de opiniões; corrupção; falta de vontade política; famílias destruídas; "esqueci profe: materiais, tarefas, pesquisas" 5 (uma alusão à fala frequente de alunos); falta da participação efetiva dos pais ou responsáveis na construção do PPP.

Nessa segunda parte pode-se verificar que aparecem termos tanto internos à rotina escolar, quanto fatores atribuídos às questões externas.

Dentre os termos discutidos - a fragmentação, a hipocrisia, o PPP, a escola como se estivesse em ilhas - verificou-se algo, posteriormente constatado durante 0 andamento da pesquisa, gerando dificuldades em maiores resultados, ou seja, a falta de comunicação e a fragmentação do currículo consequentemente do grupo de professores.

Em relação às questões externas, sabe-se que afetam diretamente 0 cotidiano escolar, mas, por outro lado, tem-se a ciência de que o nosso aluno não se apresenta sempre da maneira que gostaríamos. A escola reflete as características da sociedade e temos o desafio de entendê-la e buscar rever as metodologias constantemente.

No segundo encontro, foi iniciada a reunião surpreendendo os professores, convidando-os a realizar uma caminhada pelos espaços da escola. A mesma atividade foi realizada com os servidores administrativos, pois constata-se a dificuldade dos funcionários em se sentir parte pertencente ao lugar, para nele conquistar seu espaço e realizar um trabalho no intuito de realmente fazer a diferença. A reunião também foi utilizada para propor um novo projeto, visando o trabalho coletivo, denominado "Juntos Somos Mais".

Assim, como no encontro anterior, os professores se dividiram em dois grupos - período matutino e vespertino -, sendo que os profissionais atuantes no período noturno puderam escolher o melhor horário para participar.

A surpresa foi que nem todos conheciam os diversos ambientes da instituição, como a biblioteca e seu acervo, locais geralmente trancados ou escondidos. Também desconheciam os espaços localizados atrás das salas de aula ou da cozinha, surgindo, a partir daí uma série de ideias a serem trabalhadas para melhorar o aspecto visual da escola e o aproveitamento maior durante as aulas.

${ }^{5} \mathrm{O}$ (a) professor(a) reproduziu uma fala que ouve constantemente em sala de aula, referindo-se à frequência na qual os alunos esquecem de trazer seus materiais escolares e de executar os deveres de casa.

Revbea, São Paulo, V. 15, № 3: 163-178, 2020. 
Após a caminhada, a tarefa foi elaborar ações (tendo em mente os sonhos e as dificuldades da Oficina do Futuro) para que pudessem ser trabalhadas posteriormente.

Vejamos no Quadro 1 os pontos levantados pelos professores do período matutino:

Quadro 1: Ações elaboradas pelos professores da EE Amando de Oliveira - Matutino.

- Propor um dia para "superação" propondo organização da escola;

- Fazer um levantamento de como os responsáveis podem contribuir para cuidar do patrimônio;

- Propor atividades para despertar o sentimento de pertencimento dos alunos em relação a escola;

- Elencar pessoas responsáveis para coordenar atividades mantendo o local;

- Organizar grupos entre alunos e professores (fixos) para cuidar dos diversos espaços, elaborando atividades do antes, durante e depois;

- Estabelecer um dia "d" para alavancar o processo de cuidado do ambiente escolar;

- Trabalhar em parceria com os outros funcionários da escola (limpeza) para organizar e mante o lugar;

- Criar formas de motivar os alunos a cuidar do ambiente;

- Envolver representantes de alunos (líder de sala) para apoiar as ações de cuidado com o ambiente escolar;

- Incentivar formas de grafite e plantio de mudas na escola;

- Usar os diversos ambientes para estudo por parte dos alunos;

- Estabelecer um projeto "hora da leitura" para o uso da biblioteca;

- Ter cuidado com objetos (mesas e cadeiras) que não são utilizadas corretamente e deixadas abandonadas pelo pátio;

- Usar a biblioteca em todas as áreas do conhecimento;

- Utilizar parcerias, inclusive estagiários, para otimizar o trabalho escolar;

- Otimizar a organização do grêmio estudantil e estabelecer parcerias, inclusive para obtenção de recursos;

- Apoiar o trabalho do componente curricular de artes para releitura de obras e exposição, inclusive pintando nos muros da escola;

- Otimizar para oportunizar maior contato com a leitura.

Fonte: Alberto, 2017

É interessante separar em dois quadros, pois o quadro docente presente no matutino era, em sua maioria, composto por professores do Ensino Médio, enquanto que no vespertino a realidade presente tratava-se do Ensino Fundamental. Assim, observa-se no Quadro 2, inclusive a proposta de atividades lúdicas, por exemplo. 
Quadro 2: Ações elaboradas pelos professores da EE Amando de Oliveira - Vespertino.

- Estabelecer parcerias com profissionais das universidades, especificamente na questão ambiental (engenheiro ambiental, arquiteto, etc);

- Proporcionar acessibilidade na quadra;

- Proporcionar melhorias em pontos específicos da escola para o desenvolvimento de atividades pedagógicas;

- Realizar ações e atividades para manter os espaços organizados;

- Utilizar de forma pedagógica todos os ambientes escolares;

- Construir uma horta na escola;

- Construir um parque para os alunos;

- Buscar parcerias para efetivar atividades propostas;

- Propor formas para criação de grafite nos muros e paredes da escola;

- Envolver os alunos nas ações para o cuidado com o ambiente;

- Realizar o plantio de árvores;

- Estabelecer formas interdisciplinares para as atividades propostas;

- Confeccionar brincadeiras como, por exemplo, pintadas no chão, para os alunos.

Fonte: Alberto, 2017

Após ter em mente as ações e a importância para o trabalho envolvendo a questão ambiental, no terceiro encontro, o tempo disponibilizado foi curto, no qual houve definição para o tema a ser trabalhado na Feira Científica da Escola, realizada em 26 de novembro de 2016. Após um grande debate sobre a questão, pois o título deveria contemplar todas as áreas do conhecimento, o coletivo definiu "Cultura no Século XXI: Tecnologia e Meio Ambiente", de forma a abrir possibilidades para que todos os trabalhos pudessem ser apresentados. Sobre os resultados dessa feira científica e cultural, será discutido a seguir no item "resultados". Após prévia análise constata-se que uma minoria dos professores entende o meio ambiente em sua complexidade. Muitos se atentaram apenas a verificar trabalhos relacionados ao destino final de tudo o que foi consumido, ou seja, o reaproveitamento e a reciclagem de resíduos, sendo que nem tudo que foi apresentado teria efetivamente utilização após o evento.

Ressaltam-se trabalhos que buscaram outros caminhos, diferente dos ditos convencionais, elaborando jornais, utilizando tecnologias, ou até mesmo relacionando temas como saúde e comunicação com o ambiente em que se vive.

No quarto encontro, destinado à reelaboração do PPP, a intenção não era interferir nas decisões relacionadas ao corpo docente. Mais uma vez a observação teve papel essencial, a equipe gestora projetou o documento vigente e os professores, organizados em um semicírculo, opinaram em relação às mudanças necessárias.

A importância da (re)construção do PPP é notável, tratando-se de um 
Esse desafio tornar-se-á mais profícuo para a escola se realizado coletivamente, através da construção de um legítimo projeto pedagógico e político. Dessa forma, o projeto não deve se tornar uma construção técnica, mas um exercício da práxis; logo, da instituição de novos valores à educação. Nele realizam-se o diálogo, a explicitação de conflitos e a deliberação coletiva. Ainda propicia-se a organização de espaços individuais de formação e reflexão de uma gestão democrática orientada com princípios de justiça ambiental (WIZIACK, 2006, p. 34).

Como a Secretaria de Educação envia um modelo padrão do PPP a ser seguido - para postagem no ambiente virtual - a Educação Ambiental só foi contemplada de forma indireta, quando se fala em trabalho coletivo, preocupação com o ambiente escolar, qualidade e o conforto ambiental. Mas compartilhamos a ideia que:

Nesse processo, a EA permite que novos significados sejam atribuídos para a educação. Também permite a reflexão do caráter "instituinte" da educação, o qual necessariamente deve ser manifestado na construção desse projeto. Nele os professores não só refletem os limites de suas atividades, mas essencialmente, os da educação e da escola pública. Enfim, os aspectos recorrentes da sociedade (WIZIACK, 2006, p. 44).

Não ouve menção específica à Educação Ambiental, mas se constatou um maior entrosamento do grupo, por meio de manifestações pertinentes sobre a elaboração do documento, adequando pontos relevantes em que a questão ambiental pode ser inserida, aspecto que será detalhado em outro momento.

Tendo descrito os encontros, no item seguinte serão apresentados os resultados do trabalho realizado. Observa-se que até a redação deste texto as mudanças ainda eram notáveis, com diversas atividades envolvendo os professores.

\section{Resultados}

O projeto "Juntos Somos Mais" trouxe contribuições significativas à Escola. Foram organizados momentos para trocas de livros, implantação de horta, realização de sarau literário, ações de limpeza e organização do ambiente, reaproveitamento de materiais, dentre outros.

Provavelmente os resultados seriam mais profícuos caso a permanência dos docentes fosse maior na EE Amando de Oliveira, isso porque a quantidade de salas e as horas de trabalho não permitem que professores de Filosofia, por exemplo, tenham sua lotação de trabalho em um único local. Neste caso 
poderia haver uma maior identidade em relação ao ambiente de trabalho se a permanência fosse diária.

Uma ação de destaque no ano de 2016 foi a realização da Feira Científica e Cultural (no mês de novembro), tendo como tema "Cultura no Século XXI: Tecnologia e Meio Ambiente". Como visto anteriormente, o tema foi definido pelo grupo de professores e as turmas ficaram sob a responsabilidade de duplas constituídas por docentes de áreas diversificadas do conhecimento. Todos participaram desse evento que é destinado a mostrar a toda comunidade os trabalhos realizados na Escola durante o ano letivo. Pesquisas envolvendo lixo eletrônico, a arte utilizando produtos alternativos, ideias para um ambiente sustentável nos lares, dentre outras, foram destaques no evento.

Ideias surgiram para o aprimoramento da Feira para o ano letivo de 2017, considerando um avanço nas discussões do grupo, que observou pontos que mereciam ser revistos e refletidos, um grande exemplo é a geração de uma quantidade menor de resíduos após o evento.

Com isso, em 2017 o "Projeto Juntos Somos Mais" (não possui mais essa terminologia) ${ }^{6}$ da Escola Estadual Amando de Oliveira avançou para a realização de um Simpósio anual, atualmente contemplado na atualização do PPP. A proposta visa substituir as tradicionais provas escritas bimestrais por atividades interdisciplinares, com o objetivo de desenvolver a autonomia do estudante e a iniciação científica, no intuito de realizar uma apresentação no quarto bimestre das pesquisas produzidas durante 0 ano. Com isso há substituição da grande quantidade de papel utilizado para as apresentações usando slides e/ou banners.

As revisões periódicas do PPP também permitiram a inclusão de propostas voltadas à Educação Ambiental, conforme abordado na obra de Wiziack (2006). Os alunos colocam em prática atividades visando ao cuidado com os diversos espaços do ambiente escolar.

Inúmeras ações são realizadas durante o ano letivo no ambiente escolar e externo a ele, sendo que o primeiro bimestre é dedicado à construção de um projeto de pesquisa, com o apoio de dois orientadores por turma. Prévias são apresentadas nos dois bimestres subsequentes e uma apresentação final com os resultados obtidos acontece quando se aproxima o término do ano letivo.

Vale ressaltar que em 2019 a experiência foi realizada pelo terceiro ano consecutivo.

Atualmente o Simpósio do Amando de Oliveira incentiva a pesquisa e autonomia do aluno de diversas formas, abarcando os demais projetos de acordo com a turma, inclusive os destinados às questões ambientais. Muitos desses trabalhos têm ações na própria escola. 


\section{Considerações finais}

A pesquisa demostrou um caminho de grandes dificuldades para o desenvolvimento da Educação Ambiental. Porém, também revelou que mediante a persistência, essas dificuldades podem ser contornadas e resultados satisfatórios são constatados.

O primeiro percalço, conforme destacado, é a fragmentação das áreas do conhecimento. A rotatividade do professor de Ensino Médio, alguns por lecionar em disciplinas com baixa carga horária, revela um problema para o trabalho coletivo e a realização da pesquisa colaborativa. Desta forma, alguns docentes destacam mais durante o desenvolvimento do projeto.

Em relação ao Projeto Político e Pedagógico (PPP), a Educação Ambiental é abordada indiretamente, haja vista o formato do documento solicitado pela Secretaria de Educação (estipulando os itens necessários em sua construção). Isso não impede a realização de projetos ou outras atividades envolvendo a temática, ou mesmo que a Educação Ambiental seja contemplada em aspectos diversos de acordo com a discussão dos profissionais envolvidos na elaboração do documento.

Enxergamos a necessidade de educadores ambientais atuando como agentes transformadores, pois há dificuldade de compreensão ou de elaboração de estratégias e metodologias de trabalho em torno da questão ambiental. No preparo para a Feira Científica e Cultural da Escola, observamos a visão pautada apenas no destino dos resíduos, destacando o tema da reciclagem. Reflexões sobre o consumo, ou o próprio ambiente escolar, são casos ainda isolados, pautados em ações pontuais. Alguns aspectos alcançaram grande melhora entre o ano letivo de 2016 e meados de 2017, sendo a realização do simpósio - pautado mais em ações do que em enfeites, cartazes e brinquedos - um exemplo fundamental.

Houve imprevistos para a promoção de encontros com os docentes participantes da pesquisa durante os momentos de formação de professores. Incompatibilidades de horários, acúmulos de trabalhos, pouca disposição para mudanças de comportamentos por parte dos envolvidos, somados aos percalços provocados pela conjuntura política e a adequação de tempo para um trabalho de excelência. Mas é importante salientar que esses encontros provocaram efeitos indiretamente, mesmo sem as pessoas envolvidas fazerem menção direta à Educação Ambiental, ela está ali! Está presente no cantinho da Escola onde hoje existem vasos de plantas, em um banheiro mais bem cuidado, na preocupação com o próximo, na participação da comunidade na rotina escolar, em atividades simples, como a troca de livros, que provocam reflexões sobre o consumo e aproximam as pessoas.

Pode-se reafirmar que a Educação Ambiental não compete apenas a algumas disciplinas, mas qualquer área do conhecimento pode contribuir para ações visando o bem-estar comum, de forma interdisciplinar. Essa contribuição pode transcender os muros da escola e buscar o apoio da comunidade para a consolidação de ações efetivas visando atingir um número maior de pessoas. 


\section{Agradecimentos}

Aos professores e equipe gestora da Escola Estadual Amando de Oliveira pelo apoio à pesquisa; ao Programa de Pós-Graduação em Ensino de Ciências da Universidade Federal de Mato Grosso do Sul.

\section{Referências}

ALBERTO, H.M.R; "Amando": Educação ambiental e interdisciplinaridade formação continuada e coletiva de professores. Dissertação (Mestrado em Ensino de Ciências) - Universidade Federal de Mato Grosso do Sul. Campo Grande (MS), 2017.

BRASIL. Ministério da Educação/Ministério do Meio Ambiente.. Formando Com-vida, Comissão de Meio Ambiente e Qualidade de Vida na Escola: construindo Agenda 21 na escola, $3^{\text {o }}$ ed., rev. e ampl. Brasília: MEC, Coordenação-Geral de Educação Ambiental, 2012.

DELIZOICIV, D.; DELIZOICOV, N.C. Educação Ambiental na Escola. In: LOUREIRO, F.B.; TORRES, J.R. (orgs). Educação Ambiental: dialogando com Paulo Freire. São Paulo: Cortez, 2014.

FREIRE, P. Pedagogia do Oprimido. Rio de Janeiro: Paz e Terra, 2015.

GUIMARÃES, M. A Formação de Educadores Ambientais. Campinas, SP: Papirus, 2012, 8으. ed.

GUIMARÃES, M. A Dimensão Ambiental na Educação. São Paulo: Papirus, 2013.

LEFF, E. Saber Ambiental: Sustentabilidade, racionalidade, complexidade, poder. Petrópolis, RJ: Vozes, 2012, 9e ed.

LOUREIRO, C.F.B. Trajetória e Fundamentos da Educação Ambiental. São Paulo: Cortez, 2012, 4ㅇe.

SAITO, C.H.; FIGUEIREDO, J.B.A.; VARGAS, I.A. Educação Ambiental numa abordagem Freireana: fundamentos e aplicação. In: PEDRINI, A.G.; SAITO, C.H. (org.). Paradigmas Metodológicos em Educação Ambiental. Petrópolis, RJ: Vozes, 2014

TORRES, J.R.; FERRARI, N.; MAESTRELLI, S.R.P. Educação Ambiental Crítico-transformadora no Contexto Escolar: teoria e prática freireana. In: LOUREIRO, F.B.; TORRES, J.R. (orgs). Educação Ambiental: dialogando com Paulo Freire. São Paulo: Cortez, 2014.

WIZIACK, S.R.C. Subsídios Para a Inserção da Educação Ambiental no Projeto Pedagógico Escolar. In: VARGAS, I.A.; WIZIACK, S.R.C.; MACHADO, V.M.; MEDEIROS, Y. (org.). Educação Ambiental: Gotas de saber. Campo Grande, MS: Ed. Oeste, 2006.

ZUBEN, N.A.V. Formação de Professores: da incerteza à compreensão. In: BICUDO, A.V. (org.). Formação de Professores? Da incerteza à compreensão. Bauru, SP: EDUSC, 2003. 